\section{REFLECTIONS ON COORDINATING A MULTI-COUNTRY PAPER: A MEANS TO AN END, NOT AN END IN ITSELF!}

\section{Introduction}

Multi-country comparative health systems research is widely used to inform policy making. Examples include: the UK On-Call Facility for International Healthcare Comparisons ${ }^{1}$ and the WHO European Observatory on Health Systems and Policies. ${ }^{2}$ The International Medical Workforce Collaborative (IMWC) $^{3}$ conference, initiated in 1996, was established to promote exchange and understanding of policy approaches across countries and international collaboration in research, and evaluation and forecasting to enhance the ability of each country to respond to workforce needs. In 2010, the IMWC committee agreed to a proposal that Australia take the lead in coordinating a multi-country paper on: "Working Together: Team-Based Models of Primary Medical Care: What's Working in Complex Care Management?" As senior research fellow at the Australian Health Workforce Institute at The University of Melbourne, I agreed to take on the challenge. This paper provides reflections on my journey, the strategies I used, and key observations about the value, as a means not an end, of multicountry papers.

\section{The Premise-"Common Ground"}

All of the IMWC member countries (Australia, USA, UK, and Canada) are in the process of health care system reform due to escalating health care costs, increasing demands from an aging population, patients increasingly presenting within primary care with chronic, complex and multi-morbidity, an increasingly complex and fragmented health system, and workforce shortages and maldistribution. Team-based models of primary care workforce have emerged across all the IMWC member countries to address these challenges.

\section{The Approach}

A multi-country, comparative health systems research ${ }^{4}$ approach was chosen, as the variation in context would allow a better understanding of how similar reforms to facilitate team-based models have been implemented in different contexts. It would also enable the use of different approaches to provide opportunities to understand factors influencing the success of reforms

\section{The Challenges}

As a health services researcher, evaluator, and policy analyst, experienced in undertaking complex research designs within tight timeframes, I was faced with challenges that were all too apparent. First, I had agreed to coordinate a multi-country paper with authors (respected academics and clinicians) whom I knew only on paper, but had not worked with. The phrase "Collaborate or Die" came to mind, given that our topic title included the phrase "working together." Second, our theme focussed on several variously defined and understood topic areas: team-based care and complex care management (CCM), in countries with multiple policies and programmatic efforts at the national, regional, and local level.

\section{The Strategies}

To engage my co-authors, I reflected on the film by Kevin Costner, "Field of Dreams" and the now immortal line, "Build it and they will come" — where he built a baseball field in a cornfield and baseball legends came from all around. As Strategy 1, I developed a conceptual framework based on a realist evaluation approach ${ }^{5}$ to guide the consistent preparation of country contributions into a "single multi-country paper." Despite multiple e-mails encouraging such contributions, only 1 contribution was received. With time running out, Strategy 2 came into play"role modelling." I produced the Australian paper on what's working in CCM using team-based care. This resulted in 3 country papers, the elusive 4 th country paper nowhere to be seen. With only 1 month to go, a jointly produced, single paper seemed impossible. The last country paper came in 2 weeks prior to the conference. To ensure all country's authors' contributions were respected and contextualized, I opted to use a case-study approach. I collated the papers into 4 country-specific case studies in line with a "realist evaluation" approach to illustrate what's working and in what circumstances to support team-based models for patients with complex care needs within the primary medical care setting. To do further justice to my contributors, as topic discussant at the IMWC conference, I used 2 more strategies. First, to ensure my analysis and synthesis was systematic and transparent, I used an applied policy conceptual framework. ${ }^{6}$ Second, at the IMWC conference I structured the session so that each country author summarized key points; I provided an analysis and commentary on emerging themes. Finally, there was an opportunity for partici- 
pants to discuss findings and develop potential joint actions among IMWC member countries to optimize policy options.

\section{Key Observations}

Despite not producing a "single multi-country paper," the collaborative process enabled me to identify common issues and policy options to support the health workforce to work together to care for patients with complex care needs. ${ }^{7}$ On a pragmatic level, the process of coordinating a multi-country paper with authors in different time zones, could have been facilitated if I had given myself time to get to know who I would be working with as a way of building relationships, trust, respect, and clarity about the task, roles, and responsibilities - the underpinnings of working together. My journey has revealed that multi-country papers are desirable and potentially achievable; however, they are a means to an end, and not an end itself.

Lucio Naccarella, PbD, BSc (Hon)

The Australian Health Workforce Institute

The University of Melbourne, Australia

Acknowledgments: This account of my (Lucio Naccarella) experience of coordinating a multi-country single paper is based on my recollections and interpretations only. I thank all my co-authors (Ms Susanne LeB- outillier, Dr Amanda Mulcahy, Dr Louise Nasmith, Dr Catherine Creede, Sonya Kupka, Professor Lloyd Michener, Bobbie Berkowitz, Justine Strand de, Oliveira, Jennifer Cook, Professor Matthew Sutton, and Mr Martyn Del) as without you this journey would not have been possible. Special thanks to Professor James Buchan for comments on earlier drafts.

\section{References}

1. Department of Health. London School of Hygeine and Tropical Medicine. On-Call Facility for International Healthcare Comparisons [web site]. http://www.international-comparisons.org.uk/about.

2. World Health Organization (WHO). European Observatory on Health Systems and Policies [web site]. http://www.euro.who.int/en/ home/projects/observatory.

3. Royal College of Physicians and Surgeons of Canada. The International Medical Workforce Collaborative. http://rcpsc.medical.org/publicpolicy/imwc.php.

4. González Block MA. Comparative research and analysis methods for shared learning from health system reforms. Health Policy. 1997;42(3):187-209.

5. Pawson R, Tilley N. Realistic Evaluation. Thousand Oaks, CA: Sage Publications; 1997.

6. Ritchie J, Spencer L. Qualitative data analysis for applied policy research. In: Bryman A, Burgess R, eds. Analysing Qualitative Data. London: Routledge; 1993:173-194.

7. Naccarella L, LeBoutillier S, Mulcahy A, et al. Theme 4: Working together: team-based models of primary medical care: what's working in complex care management? Case studies from four countries. http://rcpsc.medical.org/publicpolicy/imwc/2010-IMWC12/IMWCTeam-basedModelspaper2Apri2010.pdf. 